\title{
Analysis of Microstructure and Mechanical Properties of Friction Stir Vibration Welded (FSVW) 5083 Aluminum Alloy Joints: Experimental and Simulation
}

\author{
B. Bagheri*, ${ }^{\dagger}$, and M. Abbasi** \\ *Department of Mining and Metallurgy, Amirkabir University of Technology, Tehran, 9821, Iran \\ **Faculty of Engineering, University of Kashan, Kashan, 98318, Iran
}

†Corresponding author : b.bagheri@aut.ac.ir

(Received March 3, 2019 ; Revised April 16, 2019 ; Accepted May 2, 2019)

\begin{abstract}
In the current research, friction stir vibration welding (FSVW) process was introduced for welding of A15083 alloy as a new method to improve mechanical and microstructure characteristics of joining zone. Vibration through a motor was added regularly to weld line during the friction stir welding process. Finite element method (FEM) to verify experimental results in different vibration frequencies used. The results showed that grain size in the weld region reduces as vibration frequency increases. The increasing in straining results in the improvement of dislocation density, and leads to more development of high angle grain boundaries because of dynamic recrystallization. The grain size of base metal is $64 \mu \mathrm{m}$, while it is about 17 and $9 \mu \mathrm{m}$ during FSW and FSVW respectively. Besides, strength, hardness and formability index of FSV welded samples were tremendous than that of FS welded ones. Ultimate tensile strength (UTS) increases from $180 \mathrm{MPa}$ for FSW to $225 \mathrm{MPa}$ as $48 \mathrm{~Hz}$ frequency vibration was used. The thrust force curve indicated that the time required to reach the highest thrust level as well as the peak thrust value reduce as the vibration frequency increases. This novel way can enhance the application of FSW, and it has suggested for utilization in various industries.
\end{abstract}

Key Words : Friction stir vibration welding, Finite element method, Microstructure, Mechanical properties

\section{Nomenclature}

FSW $=$ Friction Stir Welding

TWI $=$ The Welding Institute

FSVW $=$ Friction Stir Vibration Welding

S-FSVW $=$ Simulation of Friction Stir Welding

ALE $=$ Arbitrary Lagrangian-Eulerian

$\mathrm{JCP}=$ Johnson-Cook Plasticity

TRS $=$ Tool rotation speed

$\mathrm{SD}=$ Shoulder diameter

$\mathrm{WS}=$ Welding speed.

$\sigma=$ Static yield stress

$\varepsilon=$ Equivalent plastic strain

$\dot{\varepsilon}_{p}=$ Plastic strain rate for $\dot{\varepsilon}_{0}=1 s^{-1}$

$\mathrm{A}, \mathrm{B}, \mathrm{C}, \mathrm{m}, \mathrm{n}, \mathrm{a}=$ Material constants

$\mathrm{T}=$ Absolute temperature for $0 \leq T^{*} \leq 1$
$T_{\text {room }}=$ Ambient temperature

$T_{\text {melt }}=$ Melting temperature

$\Omega=$ Heat energy

$\rho=$ Material density

$\mathrm{HV}=$ Vickers hardness test

$\gamma=$ Acceleration

$\partial \Omega=$ Boundary of the domain $\Omega$

$\partial \Omega_{C}=$ Boundary of the contact surface

$\mathrm{v}_{\text {tool }}=$ Displacement of the tool

$\sigma_{n}=(\sigma . n) \cdot n=$ Contact pressure

$\mathrm{m}=$ Mas of a given volume

$\mathrm{g}=$ Gravity acceleration

$\mathrm{n}=$ Normal out warding the surface

$\mathrm{HAZ}=$ Heat-affected zone

TMAZ $=$ Thermo-mechanical affected zone

$\mathrm{WNZ}=$ Weld nugget zone

$\mathrm{Z}=$ Zener-Hollomon parameter

Journal of Welding and Joining, Vol.37 No.3(2019) pp243-253

https://doi.org/10.5781/JWJ.2019.37.3.8 
$\mathrm{R}=$ Gas constant

SEM $=$ Scanning electron microscopy

\section{Introduction}

Welding various metals have been challengeable among industries and engineers. Friction stir welding (FSW) process has been well recognized and has been many high reviews on the intricacies involved. Friction stir welding (FSW) is a solid-state welding process patented by The Welding Institute (TWI) in $1991^{1)}$. In this way, the heat produced from the friction between the welding tool (namely the shoulder and the pin) and the work-piece material with lower temperature degree than that of its melting point. Schmidt et al. ${ }^{2)}$ and Zhang et al. ${ }^{3)}$ investigated the influence of tool probe in friction stir welding. Mechanical properties of A356 Al during friction stir welding examined by Lee et al. ${ }^{4}$. They reported that microstructure of stir zone developed concerning pattern metal and also some mechanical properties such as hardness and tensile strength are elevated. The impact of the welding parameter on the substructure of the FSW joint for Al alloy studied by Kim et al. ${ }^{5}$. They found that the stir zone structure shows fine grain sizes free of dendritic structure, and also the Si particle size with increasing welding velocity reduces. The thermal distribution during the FSW process of Al's joint has investigated by Hwang et al. ${ }^{6}$. The results indicated that the weld zone with high quality as a result of controlling the maximum temperature would achieve. A three-dimensional model of the finite element method used to study thermal history and thermomechanical properties of 6061-T6 Al joint with FSW process by Chen and Kovacevic ${ }^{7)}$. Li et al. ${ }^{8)}$ examined the residual distribution of the Al alloy stiffened plate after the friction stir welding process by the finite element method. They resulted in the same residual distortion trends for the structure before and after FSW, while its deformation value was low. The numerical simulation of temperature distribution and material flow in FSW of aluminum alloys introduced by Padmanabhan et al. ${ }^{9}$. They reported that the peak temperature in the work-pieces grows up with the increasing of tool rotation speed (TRS), shoulder diameter (SD), and also welding speed (WS). Huang and Reynolds ${ }^{10)}$ studied the influence of the friction stir welding parameters upon mechanical properties of the aluminum alloy. Recently, the friction stir welding process has emerged dramatically as the preferred process in joining various $\mathrm{Al}$ alloys $1^{1-15)}$. The mechanical properties of 2024-T3 aluminum friction stir joining investigated by Sutton et al. ${ }^{16)}$. The influence of pin angle and preheating upon temper- ature distribution during FSW for copper alloy introduced by Keivani et al. ${ }^{17)}$. They found that temperature around the weld line improves by increasing pin angle. Abbasi et al. ${ }^{18)}$ applied the thermal analysis of FSW by simulation for Al alloy with different tool shapes. The results showed that straight cylindrical pins provide lower heat and corresponding temperature compared to other ones in the FSW process. The microstructure and mechanical characteristics of steel-copper joints by friction stir welding studied by Jafari et al. ${ }^{19)}$. Sato and Kokawa ${ }^{20)}$ investigated the influence of the FSW process on the hardness of AA1080 and AA5083O non-heat-treatable aluminum alloys. Weld region for AA1080 showed higher strength compared to base metal because of finer grain size. Chao et al. ${ }^{21)}$ studied the variation of heat energy and temperature generated by FSW in both work-piece and the pin tool. Zhang et al. 22) applied numerical simulation and experimental investigation of temperature distribution during FSW of AA 6061-T6. They found that there is a good agreement between each measured points by numerical simulation and experimental one. In this investigation, the strong material flow mainly happens in the area of near the tool.

In the present study, the influence of vibration on joining Al 5083 plates during FSW was investigated. The results including microstructure and mechanical properties studied by experimental and simulation. Four various vibration frequencies to study of grain size, strength, formability, hardness, and the fracture were applied. The results indicated the improvement of appearance, microstructure and mechanical properties of the weld zone by the implement of vibration during the FSW process.

\section{Materials and Methods}

In this investigation, the butt joining of Al 5083 by a thickness of $3 \mathrm{~mm}$ utilized. Samples prepared with a size of $130 \mathrm{~mm}$ (high) and $50 \mathrm{~mm}$ (width) with machined edges. To make sure that no contaminations present on the sample surface, the samples were cleaned with sandpaper and acetone. The chemical composition of the base metals was studied and the results summarized in Table 1. Table 2 shows the mechanical and thermal properties of Al 5083.

Table 1 Chemical composition and mechanical properties of $\mathrm{Al} 5083$ (wt $\%$ )

\begin{tabular}{|c|c|c|c|c|c|}
\hline $\mathrm{Fe}$ & $\mathrm{Si}$ & $\mathrm{Mn}$ & $\mathrm{Cr}$ & $\mathrm{Cu}$ & $\mathrm{Mg}$ \\
\hline 0.4 & 0.5 & 0.4 & 0.25 & 0.1 & 4.8 \\
\hline
\end{tabular}


Table 2 Mechanical and Thermal properties of Al5083

\begin{tabular}{|c|c|c|c|c|c|c|}
\hline $\begin{array}{c}\text { Ys } \\
(\mathrm{MPa})\end{array}$ & $\begin{array}{c}\text { UTS } \\
(\mathrm{MPa})\end{array}$ & $\begin{array}{c}\text { Elongation } \\
\%\end{array}$ & $\begin{array}{c}\mathrm{E} \\
(\mathrm{GPa})\end{array}$ & $\begin{array}{c}\text { Hardness } \\
(\mathrm{V})\end{array}$ & $\begin{array}{c}\text { Thermal } \\
\text { Conductivit } \\
\mathrm{y}(\mathrm{W} / \mathrm{m} . \mathrm{K})\end{array}$ & $\begin{array}{c}\text { Thermal } \\
\text { Expansion } \\
(/ \mathrm{K})\end{array}$ \\
\hline 184 & 307 & 15 & 71 & 94 & 121 & $25 \times 10^{-6}$ \\
\hline
\end{tabular}

\subsection{FSW Process}

Friction stir welding (FSW) and friction stir vibration welding (FSVW) introduced by using a milling machine. Schematic design of the method utilized to vibrate the fixture illustrated in Fig. 1. In this design, the rotation speed of the motor shaft transformed into linear movement of the fixture via the camshaft. The motor was prepared by a driver to make the possibility of the motor rotation speed change. The camshaft created in a way that it impacted on the vibration of the fixture with an amplitude of $0.5 \mathrm{~mm}$. In this study, the pin and shoulder of the tool were manufactured from carbide tungsten and M2 steel, respectively. Fig. 2 shows the schematics for the utilized tool for the FSW process in the current research.

In this research, various welding situations (Table 3) for the welding process, namely friction stir welding (FSW) and also friction stir vibration welding (FSVW) to obtain the best substructure and mechanical properties introduced. The suitable processing states occurred for the rotation speed of $1180 \mathrm{rpm}$ and traverse speed of
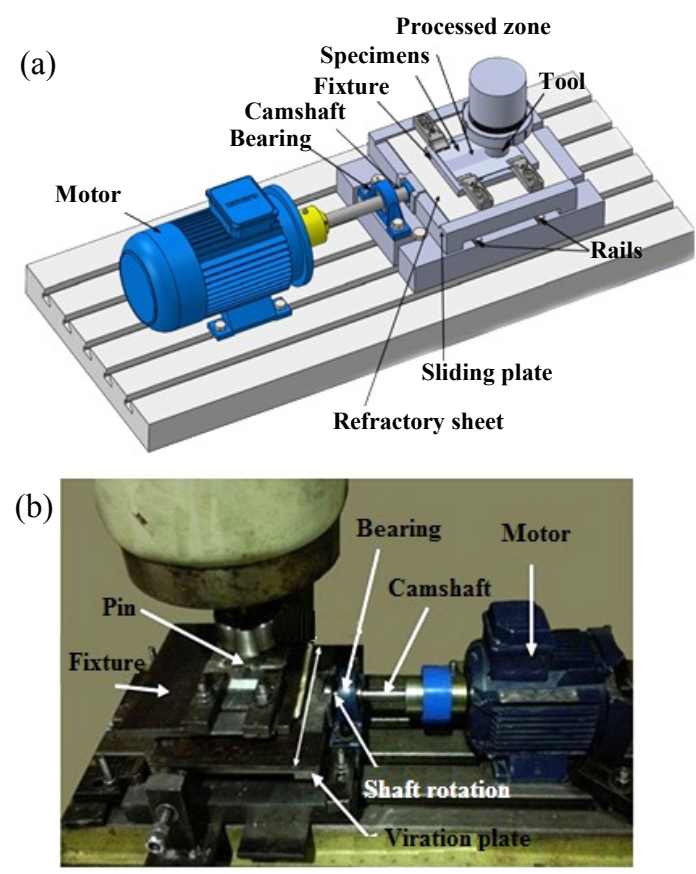

Fig. 1 Schematic design of fixture and the set used for vibration a) designed machine and b) experimental machine
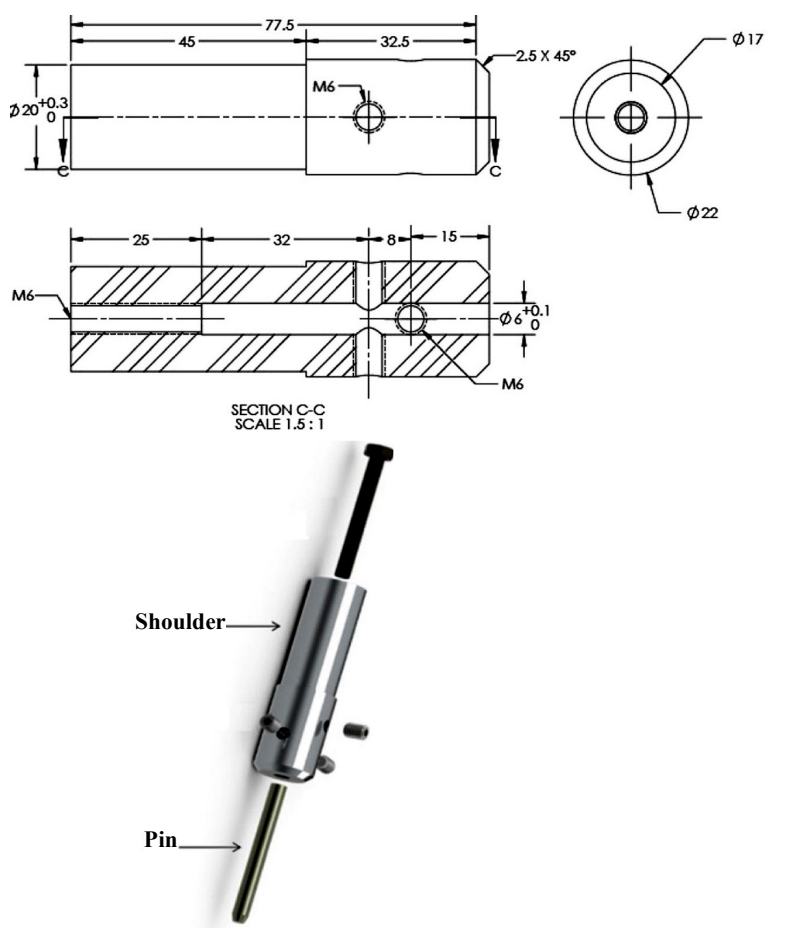

Fig. 2 View of the tools used (units are in $\mathrm{mm}$ )

Table 3 FSW process parameters.

\begin{tabular}{|c|c|c|c|c|}
\hline $\begin{array}{c}\text { Rotational } \\
\text { speed } \\
(\mathrm{rpm})\end{array}$ & $\begin{array}{c}\text { Welding } \\
\text { speed } \\
(\mathrm{mm} / \mathrm{min})\end{array}$ & $\begin{array}{c}\text { The depth } \\
\text { of pin (mm) }\end{array}$ & $\begin{array}{c}\text { Tilt angle } \\
\text { (degree) }\end{array}$ & $\begin{array}{c}\text { Vibration } \\
\text { frequency } \\
(\mathrm{Hz})\end{array}$ \\
\hline 1180 & 95 & 2.8 & 1.3 & 18 \\
\hline 1180 & 95 & 2.8 & 1.3 & 28 \\
\hline 1180 & 95 & 2.8 & 1.3 & 38 \\
\hline 1180 & 95 & 2.8 & 1.3 & 48 \\
\hline
\end{tabular}

$95 \mathrm{~mm} / \mathrm{min}$. Metallography samples from the cross sections of the welded samples prepared and then subjected to grounding, polishing, and etching. By optical microscopy, furnished through the conventional linear intercept method, the grain size was studied. (ASTM E-112 $2^{23)}$ ).

ASTM-E8 standard test to analyze the tensile testing was used $^{24)}$. The view of the tensile test sample shown in Fig. 3. From the tensile test, the strain studied by extensometer and the crosshead speed was five $\mathrm{mmmin}^{-1}$. Three tensile tests applied for each processing situation. Vickers hardness test (HV) technology was investigated for investigation of the hardness. In this method, the load was $1 \mathrm{~N}$ and the dwell time was $10 \mathrm{~s}$. The average value of 5 evaluations collected for every welding situation.

\subsection{Finite Element Method}

The simulation of material flow during FSW requires robust treatment of large deformations. Thus Abaqus/ 
Explicit software and utilizes an Arbitrary LagrangianEulerian (ALE) formulation can be easily implemented to FSW process: the material, regarded as a viscous fluid, flows across the Eulerian grid and interacts with the rotating tool. The inlet material velocity prescribed at the boundary of the domain corresponds to the traverse speed of the tool. Fig. 4 shows the finite element model of materials utilized in the FSW process. The remeshing algorithm makes be possible the Eulerian-character to allow the free surface motion to model.

The elasticity of the material modeled by an elastic plastic Johnson-Cook (JCP) constitutive equation. According to this law, the yield stress taken as a function of temperature and strain rate ${ }^{25)}$.

$$
\bar{\sigma}=\left[A+B\left(\begin{array}{l}
-p l \\
\varepsilon
\end{array}\right)^{n}\right]\left\{1+C \operatorname{Ln}\left(\frac{\ddot{\varepsilon}^{p l}}{\dot{\varepsilon}_{0}}\right)\right\}(1-\hat{\theta})
$$

Where $\ddot{\varepsilon}^{p l}, \bar{\varepsilon}^{p l}, \bar{\sigma}$ are the equivalent plastic strain rate, the equivalent plastic strain, and yield stress respectively. In this equation, $\mathrm{A}, \mathrm{B}, \mathrm{C}, \mathrm{m}, \mathrm{n}$, and $\dot{\varepsilon}_{0}$ are constants and

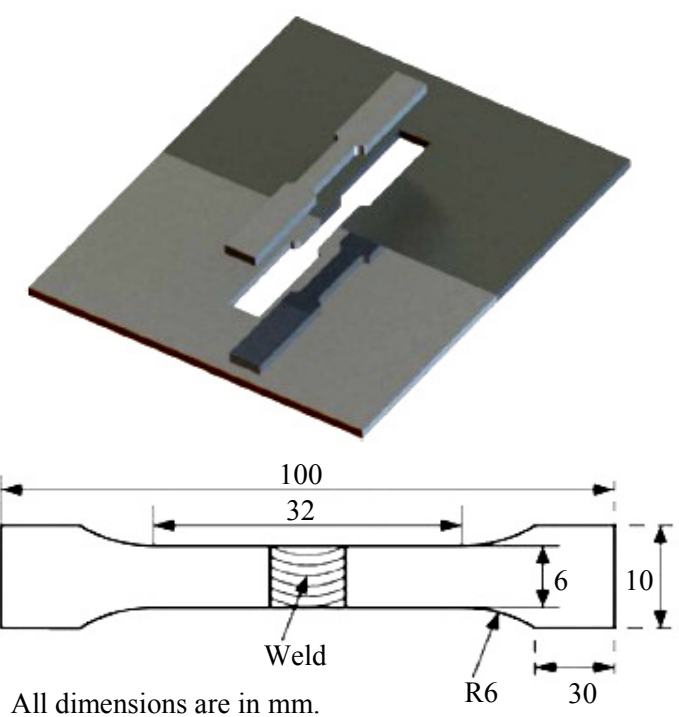

Fig. 3 View of hardness and the tensile test sample in a welded product

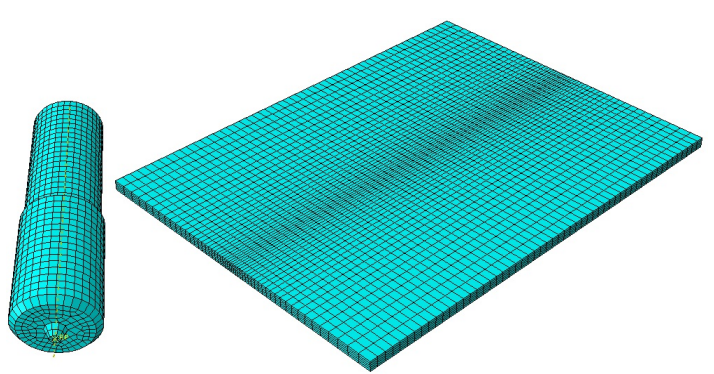

Fig. 4 Meshed work-pice and tool used in this study.
Table 4 The Johnson-Cook equations parameters for the material used

\begin{tabular}{|c|c|c|c|c|c|c|c|}
\hline $\begin{array}{c}\mathrm{A} \\
(\mathrm{MPa})\end{array}$ & $\begin{array}{c}\mathrm{B} \\
(\mathrm{MPa})\end{array}$ & $\mathrm{n}$ & $\mathrm{m}$ & $\begin{array}{c}\text { Melting } \\
\text { Temp } \\
(0 \mathrm{C})\end{array}$ & $\begin{array}{c}\text { Transition } \\
\text { Temp } \\
(0 \mathrm{C})\end{array}$ & $\mathrm{C}$ & $\varepsilon_{0}$ \\
\hline 167 & 596 & 0.551 & 1 & 630 & 25 & 0.001 & 1 \\
\hline
\end{tabular}

$\hat{\theta}$ is a dimensionless parameter used to include the influence of temperature, as indicated by:

$$
\widehat{\theta}=\left\{\begin{array}{cc}
0 & \theta<\theta_{\text {transition }} \\
\left(\frac{\theta-\theta_{\text {transition }}}{\theta_{\text {melt }}-\theta_{\text {transition }}}\right) & \theta_{\text {transition }} \leq \theta \leq \theta_{\text {melt }} \\
1 & \theta>\theta_{\text {melt }}
\end{array}\right\}
$$

In Eq. (2), $\theta, \theta_{\text {melt }}$ and $\theta_{\text {transition }}$ are the instantaneous temperature, melting point, and the transfer temperature, respectively. The Johnson-Cook factors for $\mathrm{Al}$ $5083^{26)}$ given in Table 4.

\subsection{Theoretical Formulations}

In FSW process, heat sources result from two different phenomena including the production of heat from friction at the tool/work-piece interface, and also by energy dissipation from plastic deformation of the material under the tool; therefore thermo-mechanical coupling is strongly significant to finite element analyzing ${ }^{27)}$. Mechanical equations based on a set of two physical equations including continuity and movement equations. According to the continuity equation, mass cannot be lost or gained in time:

$$
\frac{d m}{d t}=0
$$

Where " $\mathrm{m}$ " is the mass of a given volume $\Omega$. It can be express by:

$$
\frac{d m}{d t}=\frac{d}{d t}\left(\int_{\Omega} \rho(x, t) d V\right)=0
$$

Where " $\rho$ " is the density. The differentiation of equation (4) leads to the continuity equation:

$$
\frac{\partial \rho}{\partial t}+\operatorname{div}(\rho v)=0
$$

For rigid plastic materials, (neglecting elasticity ef- 
fects) the time derivative can consider as null, and incompressibility condition then write for as:

$$
\operatorname{div}(v)=0
$$

Otherwise one has:

$$
\operatorname{div}\left(\dot{\varepsilon}_{p l}\right)=0
$$

The movement equation defines as a force balance, namely dynamic forces (inertia), static forces and gravity:

$$
\rho \cdot \gamma=\operatorname{div}(\sigma)+\rho \cdot g
$$

Where $\gamma$ is the acceleration, $g$ is the gravity acceleration and $\sigma$ the stress tensor of Cauchy.

\subsection{Boundary Conditions}

Based on Fig. 5, the mechanical area $\Omega$ is called $\partial \Omega$. It can divide into various distinct boundary conditions:

$$
\partial \Omega=\partial \Omega_{c}+\partial \Omega_{L}+\partial \Omega_{v}+\partial \Omega_{T}
$$

On $\partial \Omega_{L}$ the free surface conditions impose that the normal stress is null:

$$
\sigma . n=0
$$

Where $\mathrm{n}$ is the normal out warding the surface. On $\partial \Omega_{l}$, an imposed loading situation define as:

$$
\sigma . n=T
$$

On $\partial \Omega_{V}$ the velocity is imposed following as:

$$
v=v_{0}
$$

On $\partial \Omega_{C}$ due to contact, two kinds of states imposed:

1) A non-penetration state in the normal direction, given by the Signorini equations:

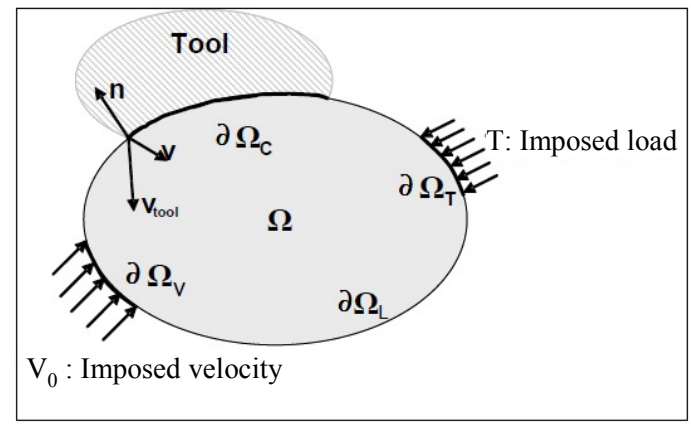

Fig. 5 View of the mechanical boundary condition of the FSW process ${ }^{27)}$

$$
\begin{gathered}
\left(v-v_{\text {tool }}\right) \cdot n \leq 0 \\
\sigma_{n} \leq 0 \\
{\left[\left(v-v_{\text {tool }}\right) \cdot n\right] \sigma_{n}=0}
\end{gathered}
$$

Where $\mathrm{v}_{\text {tool }}$ is the dislocation of the tool and $\sigma_{n}=$ $(\sigma . n) . n$ is the contact pressure.

2) A friction situation in the tangential direction, imposing the boundary shear stress:

$$
\tau_{f}=\sigma . n-\sigma_{n} . n
$$

Which shear stress is dependent on the friction laws (such as viscoelastic, Coulomb, Teresca, etc.)

\section{Results and Discussion}

\subsection{Appearance}

Fig. 6 shows the macrostructure of welded samples with the optimum measures for processing variables. According to Fig. 6, the range of welding areas of FSV welded samples, due to the vibrating movement of a specimen in FSVW process, are noted with an increasing frequency value.

The appearance of a welded product for FSW and FSVW in both experimental and FEM condition shown in Fig. 7. Improving appearance quality from FSW to FSVW is evident. Also, the temperature distribution in the FSV welded specimen is larger and smoother.

\subsection{Microstructure}

Fig. 8 indicates the microstructure of the base metal, FS and FSV welded specimens. It is clear that grains for FSV welded samples are smaller than that of FS welded ones, and both are finer than those for the base material. The principal mechanisms for grain refinement in FSW are related to dynamic recovery and recrystallization ${ }^{28,29)}$. Heat production in FSW process supplies the pos-
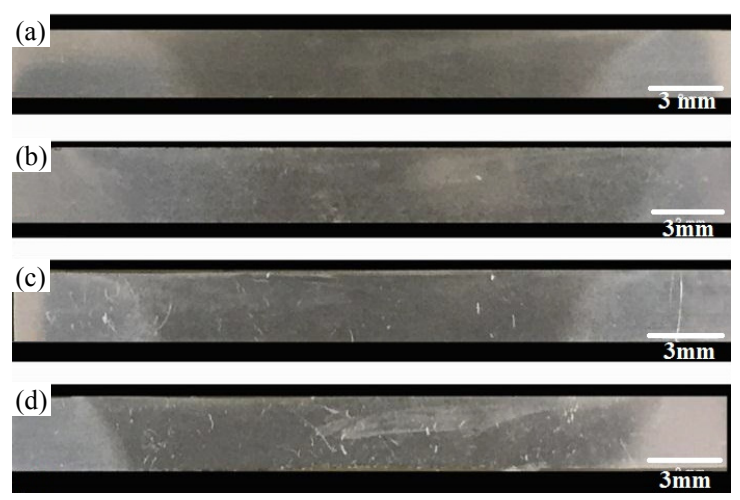

Fig. 6 Macrostructure of FSV welded specimens (a) $18 \mathrm{~Hz}$, (b) $28 \mathrm{~Hz}$, (c) $38 \mathrm{~Hz}$ and d) $48 \mathrm{~Hz}$ 


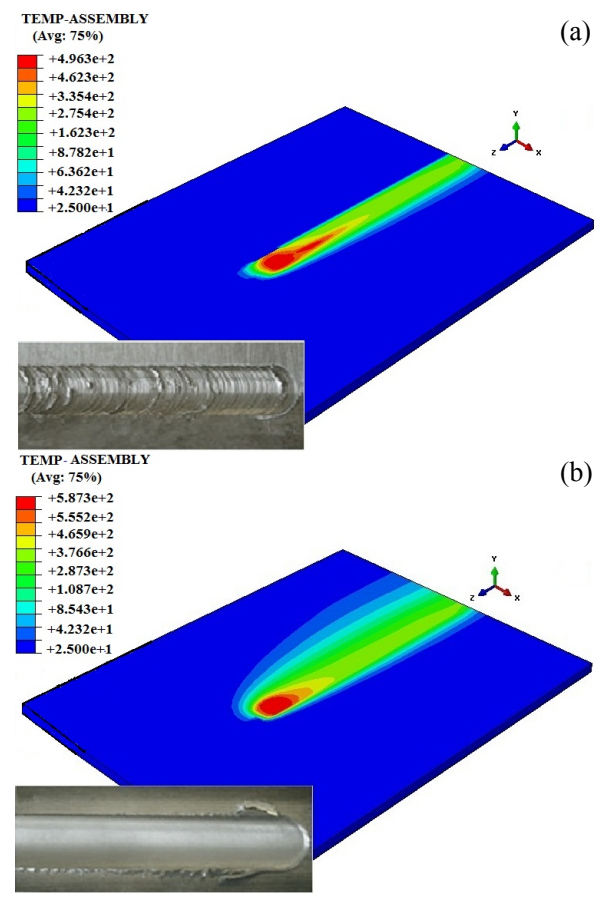

Fig. 7 The appearance of a welded product (a) FSW, and (b) FSVW (Units are ${ }^{\circ} \mathrm{C}$ )
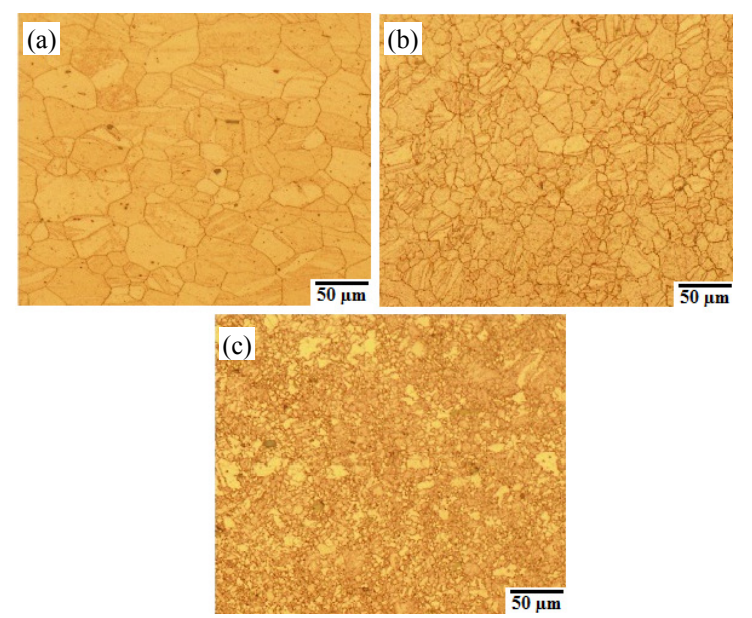

Fig. 8 Microstructure of (a) base metal (b) FS welded specimen, and (b) FSV welded specimen

sibility for dynamic recovery, so dislocations arrange themselves at low angle grain boundaries (LABs) in the dynamic recovery process; consequently, dynamic recrystallization occurs, and miss-orientation between the boundaries rises and finally LABs conversion to high angle grain boundaries $(\mathrm{HABs})^{30}$ ) . Being the vibration enhances the straining of material in FSVW and due to the movement of the tool and also the movement of work-piece; the softened material surrounded pin is deformed larger. Because of dislocation density increases as strain grows up ${ }^{31)}$; therefore, more dislocation density in FSV welded sample concerning FS welded sam-
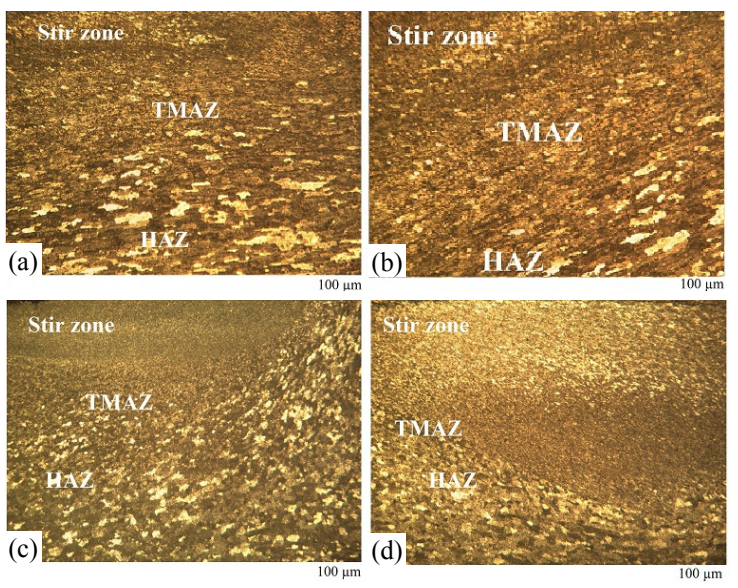

Fig. 9 Microstructure of joints developed using various FSVW vibration frequency: (a) $18 \mathrm{~Hz}$, (b) $28 \mathrm{~Hz}$, (c) $38 \mathrm{~Hz}$, and (d) $48 \mathrm{~Hz}$

ple enhanced the recrystallization and smaller grains.

The microstructure of processed samples using various vibration frequencies presented in Fig. 9. It is evident that grain size reduces as frequency applies. On the other hand, according to Zener-Hollomon relation ${ }^{32)}$ :

$$
Z=\varepsilon \exp \left(\frac{Q}{R T}\right)
$$

Where $\varepsilon$ is strain rate, $\mathrm{R}$ is gas constant, and $\mathrm{T}$ is temperature. Eq. (16) indicates the relation between Zener-Hollomon parameter (Z) and grain size (D) ${ }^{33)}$ :

$$
D^{-1}=a \ln Z-b
$$

With increasing $\mathrm{Z}$ parameter, grain size reduces.

The values of grain size for different samples were presented in Table 5.

\subsection{Fracture surfaces}

Good quality welds were those that were free of distinct and rough defects such as cracks and voids. Fracture surfaces of FS and FSV welded tensile test samples from stir region shown in Fig. 10. According to some researches, ductile metals indicate the wealth amounts of plastic deformation before to fracture in comparison to brittle metals ${ }^{34)}$. Although particles and precipitations are the main areas for void growing, FSW

Table 5 Grains size values of BM and stir zone of welded samples

\begin{tabular}{|c|c|}
\hline Specimen & Grain size $(\mu \mathrm{m})$ \\
\hline Base Metal & $64 \pm 2$ \\
\hline FSW & $17 \pm 2$ \\
\hline FSVW & $9 \pm 2$ \\
\hline
\end{tabular}



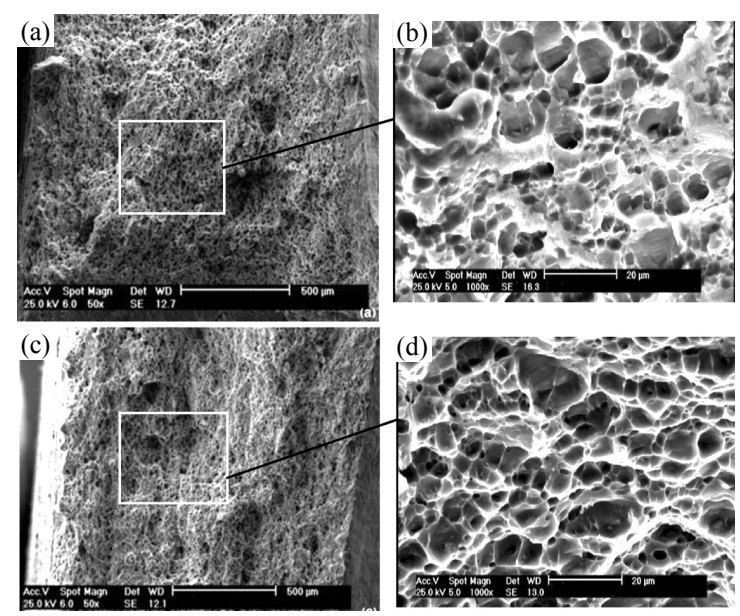

Fig. 10 SEM fracture surface of (a), (b) FS-welded sample and (c), (d) FSV-welded sample

enhances the micro-structure of parent metal and causes the breakdown of large particles and inclusions in microstructure $^{35-38)}$. Based on Fig 10, the voids for FSVwelded sample, because of having strained more before fracture, are more than that of another one.

\subsection{Stress-strain curves}

Fig. 11 shows the stress-strain curves of FS and FSV welded samples. It is clear that the ultimate tensile strength (UTS) and stress quantity of FSV is slightly higher than that of FSW. It investigated that grain boundaries hinder the movement of dislocations and enhance the strength as the volume fraction of grain boundaries levels improve ${ }^{34)}$. According to Hall-Petch correlation (17), the strength increases as grain size reduces ${ }^{36)}$ :

$$
\sigma=\sigma_{0}+k D^{-1 / 2}
$$

Besides, the FEM result shows higher values which may be related to some simulation conditions such as boundary conditions, mesh sizes, friction law, ambient

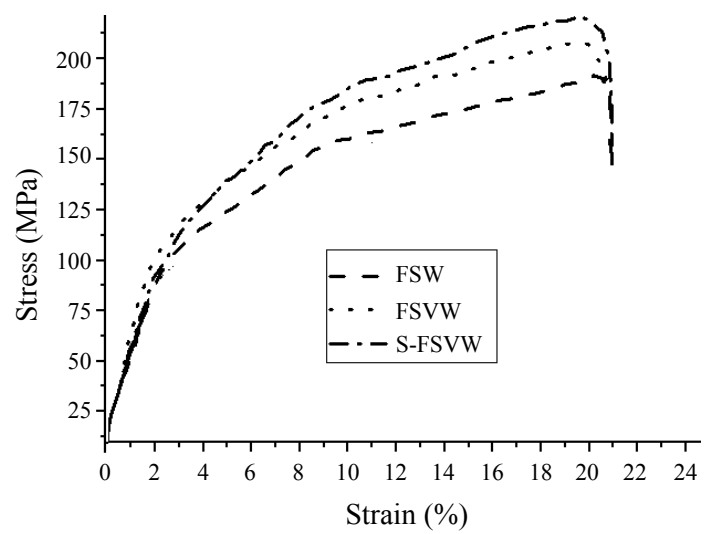

Fig. 11 Stress-strain curves of FS and FSV welded samples
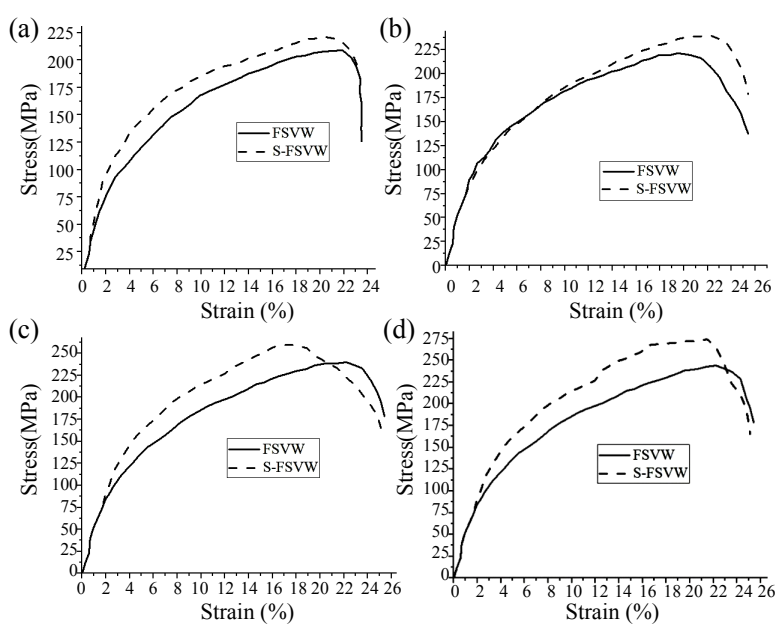

Fig. 12 Stress-strain graph of FSV welded specimens using different frequencies (a) $18 \mathrm{~Hz}$, (b) $28 \mathrm{~Hz}$, (c) $38 \mathrm{~Hz}$, and (d) $48 \mathrm{~Hz}$

temperature, etc. Finally, it should indicate that increasing the stress value in FSVW from FSW process is slightly higher compared to FSW from base metal, which the reason may relate to vibration and consequently the impact of vibration on grain size.

Fig. 12 compares the stress-strain graph of FSV welded samples in both experimental and simulation conditions using different vibration frequencies. Based on data in Fig. 12, the UTS and stress values increase as vibration frequency increases. The lower grain size of FSV welded sample causes a higher volume fraction of grain boundaries; therefore, higher strength will be obtained.

\subsection{Thrust force}

The thrust force variation during plunge testing at various vibration frequencies as shown in Fig. 13. The time

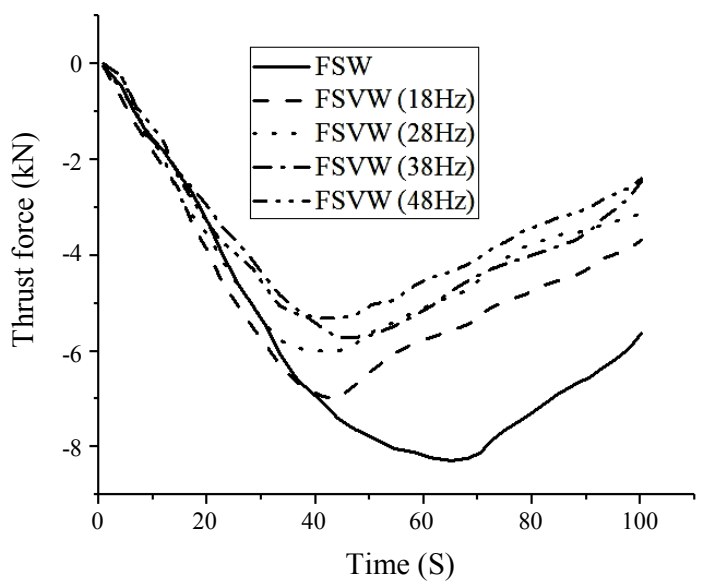

Fig. 13 Thrust force changes for different vibration frequency 


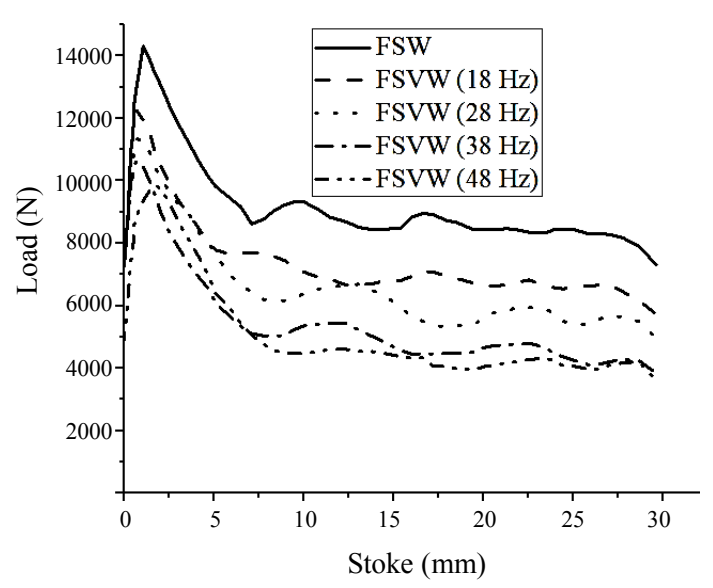

Fig. 14 Tool force along the axial direction of the tool

required to reach the highest thrust level and the peak thrust value reduces as the vibration frequency increase from 18 to $48 \mathrm{~Hz}$ and is consistent with the lower viscosity values in plunge tests produced using high frequency.

When the vibration frequency changed, the variation of the tool force along the axial direction of the tool changed, too (Fig. 14). It can see that the forces reduce with the increase in vibration frequency. The tool force in the axial direction is increased in the plunge period and reaches its maximum at the initial time of the translational stage. When the tool keeps moving along the welding line, the axial force reduces. It has known that dislocation density increment with strain increase as strain rate and temperature increase. The authors believe that increasing the vibration is accompanied by tool transverse and rotation movements. Consequently, the maximum value of the tool force due to more deformation and strain will be decreased.

\subsection{Hardness}

Fig. 15 shows profiles of micro hardness along a line at the mid-thick position on the transverse cross-section of joints welded at different vibration frequencies in both experimental and FEM conditions. It is evident that at about $15 \mathrm{~mm}$ from the weld centerline, hardness starts to reduce and reach a minimum value at $9 \mathrm{~mm}$ from the weld center line. The minimum points were located on both sides of the HAZ. As coming to the weld centerline through SZ beyond that minimum point, hardness increases and reach equal value again to that of BM. It can be related to grain size impact. It has known that grains in the stir zone are excessively small and they are co-axial due to severe plastic deformation which happens in the stirring area ${ }^{39)}$. The grains in TMAZ deform less than those in stir area, and the grains within the HAZ almost did not change. The presence of vibration also decreases the size of grains. An

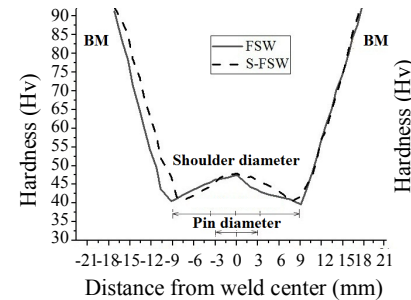

(a)

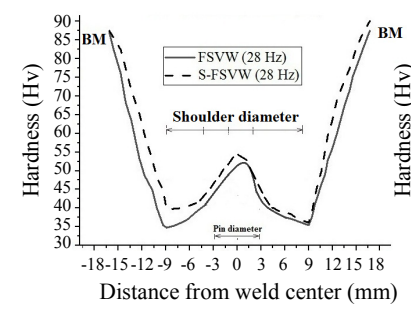

(c)

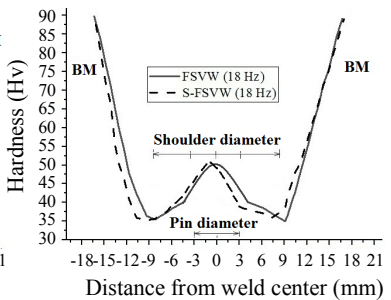

(b)

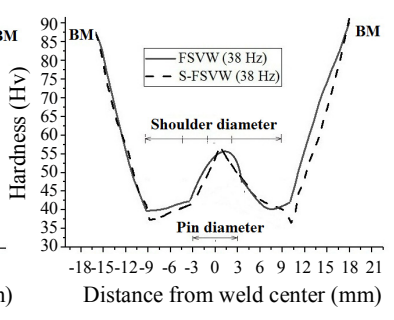

(d)

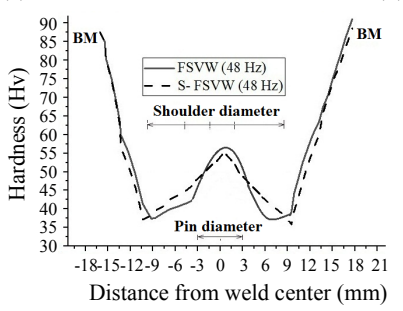

(e)

Fig. 15 Hardness section at mid-thickness transverse to welding lines of the weld joint for (a) FSW, (b) FSVW with $18 \mathrm{~Hz}$, (c) FSVW with $28 \mathrm{~Hz}$, (d) FSVW with $38 \mathrm{~Hz}$, and (e) FSVW with $48 \mathrm{~Hz}$

Table 6 Hardness changing in stir area of FS and FSV welded samples using various vibration frequencies

\begin{tabular}{|c|c|c|}
\hline $\begin{array}{c}\text { Vibration frequency } \\
(\mathrm{Hz})\end{array}$ & $\begin{array}{c}\text { Stir zone hardness }(\mathrm{Hz}) \\
\text { (exprimental) }\end{array}$ & $\begin{array}{c}\text { Stir zone hardness } \\
(\mathrm{Hz})(\mathrm{FEM})\end{array}$ \\
\hline 18 & $49 \pm 2$ & $44 \pm 2$ \\
\hline 28 & $53 \pm 2$ & $47 \pm 2$ \\
\hline 38 & $57 \pm 2$ & $49 \pm 2$ \\
\hline 48 & $57 \pm 4$ & $51 \pm 2$ \\
\hline
\end{tabular}

impediment to dislocations' motion increases as grain size reduces and correspondingly, hardness increases.

Maximum hardness values of stir zone center for specimens FSV welded using different frequencies have presented in Table 6. It is tremendous that hardness of stir zone from $49 \pm 2$ increases to $57 \pm 4$ as vibration frequency increases from 18 to $48 \mathrm{~Hz}$.

\subsection{Formability index analysis}

Fig. 16 shows the formability index of FSV welded samples in different vibration frequencies. Formability has defined by UTS $\times$ EL where UTS and EL indicate ultimate tensile strength and elongation respectively which provided the ability of the material to absorb energy be- 


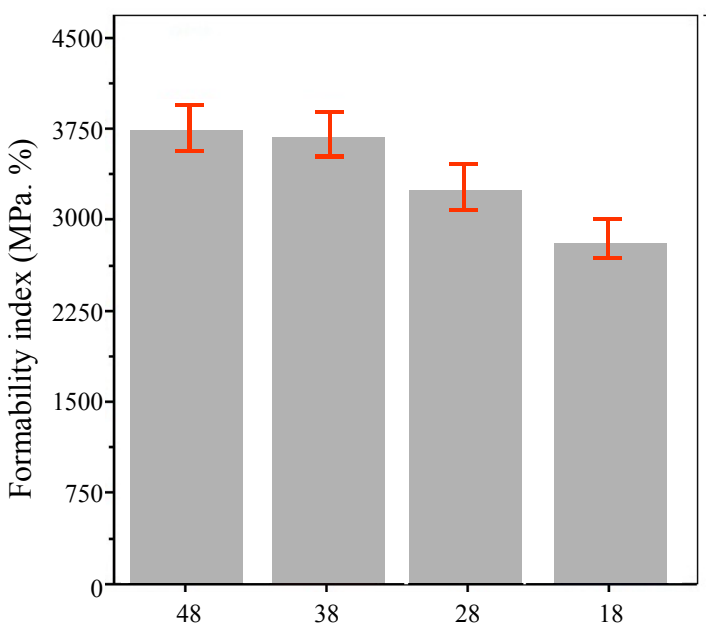

Fig. 16 Formability index of samples FSV welded using various frequency values

fore failure ${ }^{40)}$. This result endorses the results from Fig. 15 and Table 5. The formability index of FSV welded samples increases as vibration frequency increases.

One meaningful point in this study is that an oscillation frequency of 38 cycles/s, the highest strength, and hardness qualities achieved and they don't experience remarkable change as vibration frequency enhances. It may because of the relation between strain and dislocation generation in work hardening process is not linear, and it is a power law ${ }^{41)}$. At low values of strain, there is rapidly increasing in dislocation production while this trend reduces at high values.

\section{Conclusion}

In the current research, a new way introduced to enhance the characteristics of substructure and mechanical properties of $5083 \mathrm{Al}$ alloy using FSW. This process was entitled friction stir vibration welding (FSVW). The work-piece is vibrated normal to processing line in FSW. The finite element method (FEM) to verify experimental results utilized, too. It has concluded that:

- Presence of vibration during the FSW process caused in more straining of material in the welded area and improved the dynamic recovery and recrystallization and correspondingly grew up the grain refinement. Grain size increases from $64 \mu \mathrm{m}$ to around $9 \mu \mathrm{m}$ for base metal and friction stir vibration welded sample, respectively.

- A good agreement between experimental and FEM data observed. Some discrepancy between them relates to simulation conditions such as boundary, load, and mesh conditions.

- Mechanical properties such as hardness, strength andformability index increase as vibration frequency increases. The hardness of stir zone increases from $42 \mathrm{Hv}$ to $51 \mathrm{Hv}$ for FSW and FSVW respectively.

- The vibration leads to increase in material flow velocity and strain rate and enlargement of the flow region and deformation region in FSVW process. Also, it has noted that changing and improving mechanical and microstructure characteristics in certain vibration frequencies happened because of the power law.

ORCID: B. Bagheri: http://orcid.org/0000-0002-7353-1414 ORCID: M. Abbasi: http://orcid.org/0000-0002-4829-8083

\section{References}

1. Thoms W.M, Nicholas E. D, Need Ham J. C and Murch M. G, Friction stir butt welding: International patent application No. PCT/GB92/02203, GB patent application No. 9125978.8, (1991)

2. Schmidt $\mathrm{H}$ and Hattel J, Modelling heat flow around tool probe in friction stir welding, Science Technology Welding and Joining, 10 (2) (2005), 176-186 https://doi.org/10.1179/174329305X36070

3. Zhang Z and Wan Z. Y, Predictions of tool forces in friction stir welding of AZ91 magnesium alloy, Science Technology Welding and Joining, 17 (6) (2012), 495-500 https://doi.org/10.1179/1362171812Y.0000000039

4. Lee W. B, Yeon Y. M and Jung S. B, The improvement of mechanical properties of friction-stir-welded A356 Al alloy, Materials Science and Engineering A, 355 (2003), 154-159 https://doi.org/10.1016/S0921-5093(03)00053-4

5. Kim Y. G, Fujii H, Tsumura T, Komazaki T and Nakata $\mathrm{K}$, Effect of welding parameters on microstructure in the stir zone of FSW joints of aluminum die casting alloy, Materials Letters, 60 (2006), 3830-3837

https://doi.org/10.1016/j.matlet.2006.03.123

6. Hwanga Y. M, Kanga Z. W, Chioua Y. CH and Hsu H. $\mathrm{H}$, Experimental study on temperature distributions within the workpiece during friction stir welding of aluminum alloys, International Journal of Machine Tools \& Manufacture, 48 (2008), 778-787

https://doi.org/10.1016/j.ijmachtools.2007.12.003

7. Chen C. M and Kovacevic R, Finite element modeling of friction stir welding- thermal and thermomechanical analysis, International Journal of Machine Tools \& Manufacture, 43 (2003), 1319-1326

https://doi.org/10.1016/S0890-6955(03)00158-5

8. Yan D. Y, Wu A. P, Silvanus J and Shi Q. Y, Predicting residual distortion of aluminum alloy stiffened sheet after friction stir welding by numerical simulation, Materials \& Design, 32 (2011), 2284-2291

https://doi.org/10.1016/j.matdes.2010.11.032

9. Padmanaban R, Ratna Kishore V and Balusamy V, Numerical Simulation of Temperature Distribution and Material Flow During Friction Stir Welding of Dissimilar Aluminum Alloys, Processing and Engineering, 97 (2014), 854-863 
https://doi.org/10.1016/j.proeng.2014.12.360

10. Huang X, and Reynolds A. P, Effects of the friction stir welding process variants on residual stress, Science Technology Welding and Joining, (2017), 279-286 https://doi.org/10.1080/13621718.2017.1377335

11. Squillace A, Segreto T, Prisco U and Campanile G, Optimization of Friction Stir Welds of Aluminium alloys. IPROM, 135 (2006), 189-195

12. Donnetham B and Watthanasikul S, Comparison of the friction stir welding of aluminium alloy AA6063-T6 between cylindrical and rounded head, IE network conference, (2007)

13. Elangovan $\mathrm{K}$ and Balasubramanian V, Influences of tools pin profile and tool shoulder diameter on the formation of friction stir processing zone in AA6035 aluminium alloys. Materials and Design 29 (2008), 362- 373 https://doi.org/10.1016/j.matdes.2007.01.030

14. Vural M, Ogur A, Cam G and Ozarpa C, On the friction stir welding of aluminium alloys EN AW 2024-0 and EN AW 5754-H22. Material Science and Engineering A, 28 (2007), 49-54

15. Cavaliere $P$ and Cerri E, Mechanical response of 2024-8011 aluminium alloys joined by Friction Stir Welding. Journal of Materials Science, 40 (2005), 36693679

https://doi.org/10.1007/s10853-005-0474-5

16. Sutton M. A, Reynolds A. P, Wang D. Q and Hubbard C. R, A study of residual stresses and microstructure in 2024-T3 aluminum friction stir butt welds, Journal of Engineering Materials and Technology ASME, 124 (4) (2002), 215-221

https://doi.org/101115/1.1429639

17. Keivani R, Bagheri B, Sharifi F, Ketabchi M and Abbasi M, Effects of pin angle and preheating on temperature distribution during friction stir welding operation", Transaction of. Nonferrous Metalls Society of China, 23 (2013), 2708-2713 https://oi.org/10.1016/S1003-6326(13)62788-0

18. Abbasi M, Bagheri B and Keivani R, Thermal analysis of friction stir welding process and investigation into affective parameters using simulation, Journal Mechanical Science and Technology, 29 (2) (2015), 861-866 https://doi.org/10.1007/s12206-015-0149-3

19. Jafari M, Abbasi M, Poursina D, Gheysarian A and Bagheri B, Microstructures and mechanical properties of friction stir welded dissimilar steel-copper joints, Journal Mechanical Science and Technoligy, 31(3) (2017), 1135-1142

https://doi.org/10.1007/s12206-016-1217-z

20. Sato Y and Kokawa H, Microstructural Factors Go- verning Mechanical Properties in Friction Stir Welds, Key Engineering Materials, 346 (2007), 1493-1496 https://doi.org/10.4028/KEM.345-346.1493

21. Chao Y. J, QI X and Tang W, Heat transfer in friction stir welding experimental and numerical studies, ASME Journal of Manufacturing Science and Engineering, 125 (2003), 138-145 https://doi.org/10.1115/1.1537741

22. Zhang J, Shen Y, Li B, Xu H, Yao X, Kuang B and J. Gao, Numerical simulation and experimental investigation on friction stir welding of 6061-T6 aluminum alloy, Journal of Materials and Design, 60(2014), 94-101 https://doi.org/10.1016/j.matdes.2014.03.043

23. ASTM-E112-13, Standard test methods for determining average grain size, ASTM International, West Conshohocken, (2003) https://doi.org/10.1520/E0112-13

24. ASTM-E8M, Standard test methods of tension testing of metallic materials [metric], Annual book of ASTM standards, vol 3.01. American Society for Testing and Materials, (2003)

https://doi.org/10.1520/E0008_E0008M-16A

25. ABAQUS/6.14.2, Providence, RI, USA: Dassault Systems Simulia Corp, (2016)

26. Yalavarthy H, Friction stir welding process and material microstructure evolution modeling in 2000 and 5000 series of aluminum alloys. All Thesis, Clemson University, (2009) https://tigerprints.clemson.edu/all_theses/745

27. Guerdoux S, Numerical simulation of the friction stir welding process, Mechanics [physics.medph]. École Nationale Supérieure des Mines de Paris, (2007) https://pastel.archives-ouvertes.fr/tel-00271234

28. Abbasi M, Bagheri B, Dadaei M, Omidvar H and Rezaei M, The effect of FSP on mechanical, tribo-logical and corrosion behavior of composite layer devel-oped on magnesium AZ91 alloy surface, Inernational Journal Advanced Manufacturing and Technology, 177 (2015), 2051-2058 https://doi.org/10.1007/s00170-014-6577-x

29. Mishra R. S and Ma Z. Y, Friction stir welding and processing, Materials Science and Engineering R: Reports, 50 (2005), 1-78

30. Kaibyshev R, Shipilova K, Musin F and Motohashi Y, Continous dynamic recrystallization in an Al-Li-Mg-Sc alloy during equal-channel angular extrusion, Material Science and Engineering A, 396 (2005), 341-351 https://doi.org/10.1016/j.msea.2005.01.053

31. Hull D and Bacon D. J, Introduction to dislocations, Elsevier Ltd, $5^{\text {th }}$ Ed., USA, (2011)

E-Book ISBN: 9780080966731

32. Callister W. D, Materials science and engineering: an introduction, Wiley, USA, (2007)

ISNB: 10:047173696-1

33. Chang C. I, Lee C. J and Huang J. C, Relationship between grain size and Zener-Holloman parameter during friction stir processing in AZ31 Mg alloys. Script Materials, 51 (2008), 509-514 https://doi.org/10.1016/j.scriptamat.2004.05.043

34. Diter G. E, Mechanical Metallurgy, McGraw-Hill Book Company, Singapore, (1988) https://doi.org/10.1016/j.scriptamat.2004.05.043

35. Zhang W. W and Cong S, Failure analysis of SUS304 sheet during hydro-bulging based on GTN ductile damage 
model, International Journal Advanced Manufacturing and Technology, 86 (2016), 427-435

https://doi.org/10.1007/s00170-015-8199-3

36. Uthaisangsuk V, Microstructure based forma-bility modeling of multiphase steels, Ph.D. Thesis, IEHK, RWTHAachen, (2009)

37. Abbasi M, Shafaat M. A, Ketabchi M, Haghshenas D and Abbasi M, Application of the GTN model to predict the forming limit diagram of IF-steel, Journal Mechanical Science and Technology, 26 (2012), 345- 352 https://doi.org/10.1007/s12206-011-1038-z

38. Azizieh M, Bahadori R, Abbasi M, Yoon E. Y and Kim H. S, Effect of friction stir processing on the microstructure of pure magnesium castings, International Journal Casting Materials Research, 28 (2015), 345-351 https://doi.org/10.1080/13640461.2015.1106780
39. Ghanbari D, Kasiri Asgarani M, Amini K and Gharavi, Influence of heat treatment on mechanical properties and microstructure of the Al2024/SiC composite produced by multi-pass friction processing, Measurement, 104 (2017), 151-158 https://doi.org/10.1016/j.measurement.2017.03.024

40. Gheysarian A and Abbasi M, The effect of aging on microstructure, formability and springback of Ti-6Al$4 \mathrm{~V}$ titanium alloy, Journal Material Engineering and Performance, 26 (2017), 374-382 https://doi.org/10.1007/s11665-016-2431-7

41. Bulatov V and Cai W, Computer Simulations of Dislocations, Oxford Materials, 243-249 (2006)

ISBN-13: 978-0198526148 